\title{
Financing Health Services in Poland: New Evidence on Private Expenditures
}

\author{
Mukesh Chawla, PhD \\ Senior Health Economist and Department Associate \\ Department of Population and International Health \\ Harvard School of Public Health \\ 665 Huntington Avenue, Bldg 1-1210 \\ Boston, MA 02115, USA \\ Tel: (617) 432-0998; Fax: (617) 432-2181 \\ email: mchawla@hsph.harvard.edu \\ Peter Berman, MSc, PhD \\ Associate Professor of International Health Economics \\ Harvard School of Public Health \\ 665 Huntington Avenue, Bldg 1-1210 \\ Boston, MA 02115, USA \\ Tel: (617) 432-4610; Fax: (617) 432-2181 \\ email: pberman@hsph.harvard.edu
}

Dorota Kawiorska, M.S.

Fellow

Academy of Economics

Racowicka 20, Krakow, Poland 


\section{Table of Contents}

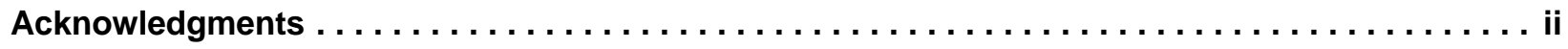

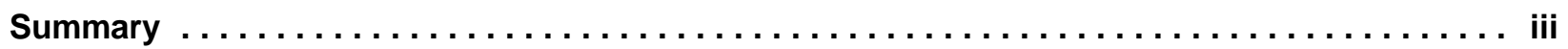

1. Introduction $\ldots \ldots \ldots \ldots \ldots \ldots \ldots \ldots \ldots \ldots \ldots \ldots \ldots \ldots \ldots \ldots \ldots \ldots \ldots \ldots \ldots \ldots$

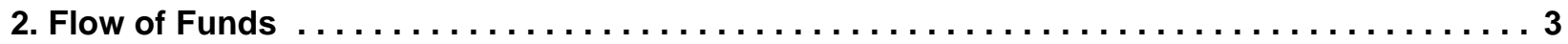

3. Purpose of the Present Study $\ldots \ldots \ldots \ldots \ldots \ldots \ldots \ldots \ldots \ldots \ldots \ldots \ldots \ldots \ldots \ldots \ldots$

4. Survey: Purpose and Methodology $\ldots \ldots \ldots \ldots \ldots \ldots \ldots \ldots \ldots \ldots \ldots \ldots \ldots \ldots$

5. National Health Accounts Revisited $\ldots \ldots \ldots \ldots \ldots \ldots \ldots \ldots \ldots \ldots \ldots \ldots \ldots \ldots$

6. Survey Findings on Out-Of-Pocket Expenditure $\ldots \ldots \ldots \ldots \ldots \ldots \ldots \ldots \ldots \ldots \ldots$

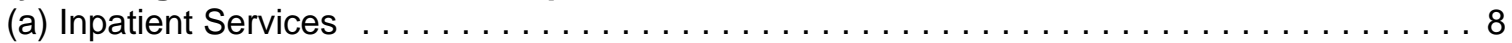

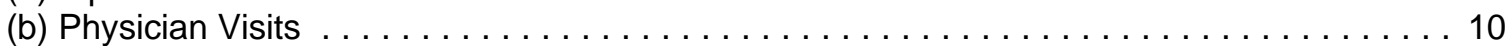

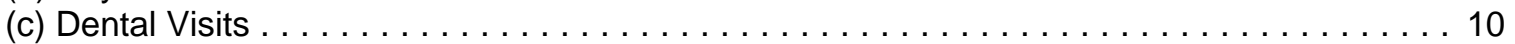

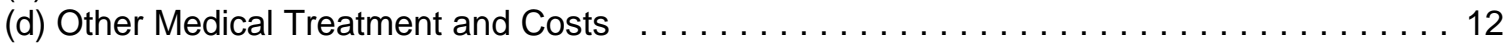

(e) Envelope Payments . . . . . . . . . . . . . . . . . . . . . . . . . 12

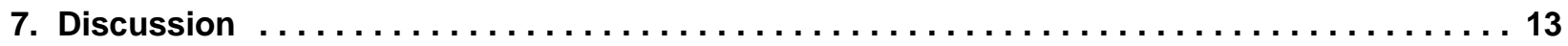

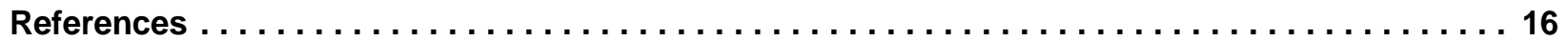




\section{Acknowledgments}

We are grateful to Tom Bossert, Alex Preker and Michael Reich for valuable comments and suggestions. Barbara Morawiec provided excellent research assistance. We alone are responsible for remaining errors. This research was conducted under the auspices of the Data for Decision Making Project at the Harvard School of Public Health and funded by the United States Agency for International Development (USAID), cooperative agreement no. DPE-5991-A-00-1052-00. 


\section{Summary}

This paper estimates total expenditure on health care in Poland in 1994 and provides new evidence on high levels of private spending on health care. The analysis shows that health care expenditures in Poland are higher than has usually been maintained, and are comparable with the prevailing levels in many other European countries. Private expenditure on health is a significant proportion of total expenditure on health, and in particular on financing outpatient care. Available evidence indicates that informal payments made by patients to physicians contribute as much as double of the physician's salary, and thus form an important source of earnings for physicians. This situation of high private expenditures on health care and informal payments to physicians is likely to be true of other transitional economies of Central and Eastern Europe as well. One policy implication that emerges is these transitional economies face a big challenge in managing existing resources, as opposed to finding new resources, in the health sector more effectively to meet the health care needs of their population. The paper highlights the need for better understanding of the current availability and distribution of resources in the health sector and their directions of flow, in both public and private sectors, and suggests using tools such as National Health Accounts to track and monitor changes in the financing of the health care system.

Keywords: Health financing; Poland; Private expenditure, Informal payments, National Health Accounts 


\section{Introduction}

Free and general access to health care services, guaranteed by the constitution in 1952, has long been considered the foundation of the Polish health care system. Accordingly, the national budget of the government has historically been the main source of health financing. Total health care expenditure in Poland, public and private, is reported to be between 4 - 5\% of GDP (1), which is quite similar to that of several other East European countries. However, in comparison with OECD countries, the health care expenditure in Poland is much lower. For instance, health care expenditure as a percentage of GDP in Poland is quite similar to Yugoslavia, Romania and Hungary, who spend around 5\% of GDP, and is lower compared to West European countries like Austria, Germany and Sweden, where expenditure on health care has averaged between $8 \%$ to $10 \%$ of GDP.

In making these comparisons, however, it is important to note that in Poland, like in other socialist countries, the calculation of national income before 1991 was based on the "material budget estimates" which accounted only for the "productive" sphere in economic activities to the exclusion of non-material outcomes. Thus, services such as health care, culture, and education are not accounted for in computing national income. This has the effect of underestimating national income, and to this extent makes international comparisons difficult. However, a more serious issue in any discussion of health expenditure arises when a significant amount of health care expenditure goes unreported and unrecorded. While government budget figures may represent fairly accurate estimates of public expenditure, private out-of-pocket expenditure, either at government facilities or in private hospitals and clinics, is almost totally unrecorded. Public services may receive some financing from private sources through direct user fees and other payments, and in the absence of any requirement on reporting these figures to the Ministry of Health, even these legitimate earnings in public facilities may go unreported.

Estimating the actual size of expenditure on health in Poland is particularly important in view of the proposed health care reforms, particularly the insurance laws. Securing stable financing and a wider support base for the health sector will, no doubt, be an important factor in the successful implementation of these reforms, and to this extent it will be very useful to have a good idea of the population's willingness and ability to pay as reflected in out-of-pocket expenditures incurred by the people.

This paper uses information from various sources to estimate total expenditure on health care in Poland. We show that total expenditure of health care in Poland has been underestimated, especially the component of private out-of-pocket payments in public facilities. Our study highlights the need of a more detailed analysis of health expenditure, particularly private expenditure. Our analysis also shows the vast potential of using private expenditure for supplementing public funds in financing provision of health care in Poland, and of diverting public funds from those areas of health care provision most likely to attract private funds (such as outpatient care) to those areas where private expenditure is low (such as inpatient care).

The rest of the paper is organized as follows. In Section 2 we describe the flow of funds in the health sector. Previous studies are reviewed and purpose of the present study is discussed in Section 3. The 1994 survey is described in Section 4, and the new data available from this survey is used to update the national health accounts, which is presented in Section 5. Specific details on out-of-pocket payments are described in Section 6, and the paper ends in Section 7 with a discussion of possible implications. 


\section{Flow of Funds}

Production and delivery of health services in Poland are financed from both public and private funds. Public funds include central budget and regional budget funds, quasi-budget funds and other public funds. Private expenditures on health care take the form of out-of-pocket payments by consumers of health care. With the provision of health care largely concentrated in the public sector, private expenditure is typically used to finance purchase of drugs, board and lodging, and other miscellaneous expenditures by individuals in public facilities. The flow of funds in the public sector is fairly well recorded, though not much information is available on private funding.

Budgetary funds are the major source of public financing of the health sector. The budget for the health sector comprises a central component for the Ministry of Health ( $\mathrm{MOH}$ ) and a regional component for the 49 administrative units, known as the "voivodships". The central budget is primarily used to fund purchase of drugs (approximately $32 \%$ of the budget) and providing services in clinical hospitals (approximately $29 \%$ of the budget). Expenditure on the medical schools and medical academies accounts for about $12 \%$ of the budget, with the remaining going to centrally financed sanatoria (about $9 \%$ ), special programs like social welfare, AIDS prevention, etc. (about $2.5 \%$ ) and administration (less the $0.3 \%$ ). Other ministries that provide health services are the Ministries of Defense, Interior, Transportation and Industry.

The central budget (2) contributes only about $15 \%$ of total budget outlay on health care (3). Most of the major health care programs are financed through the regional budgets, which fund the voivodship health authorities and a number of independent municipalities, or "gminas". These voivods and gminas receive their budgets directly from the Ministry of Finance (MOF), not the $\mathrm{MOH}$. The regional budgets support a huge network of hospitals and clinics. This network includes more than four hundred integrated health and social service units, called Zespol Opieti Zdrowotnej (ZOZ) which serve the 49 voivodships and provide inpatient and outpatient care. Major expenditure programs at the voivodship level include the ZOZs drugs, voivodship hospitals, sanatoria, TB services, blood stations, nurseries and ambulance and rescue services.

The central and voivod budgets together constitute around $90-95 \%$ of the total public expenditure on health services. Other sources of finance that contribute the remaining $5 \%$ comprise grants from central budget, also known as "quasi-budget" funds (3) and non-budget public funds. Quasi-budget funds are specifically earmarked for certain programs, of which the anti-alcoholic program is probably the most important.

Other public non-budget funds include collections from voluntary fees, donations, contributions of social organizations like the Red Cross and the Associations of Catholic "Caritas", funds from public enterprises and funds from manufacturing cooperatives employing the disabled.

It is possible to construct National Health Accounts $(4,5)$ based on public expenditure and use data (table 1). The data show that $24 \%$ of the regional budget is spent on providing outpatient care and $50 \%$ on inpatient care. Salaries constitute the largest component of the budget, accounting for almost $80 \%$ of the outpatient care budget and $64 \%$ of inpatient care budget.

However, such an analysis does not account for private spending and other non-budget sources of funds (note that the relevant columns in table 1 are blank). In the absence of reliable information on the magnitude and type of private expenditure on health care, analysis based on such NHA could be underestimating both the total amount spent in Poland on health care, and the pattern of use of various health services. In this paper we present an estimate of private expenditure in an attempt to fill this gap. 
Table 1: National Health Accounts: Sources and Uses, 1994 (million zloty; US $\$ 1=24,372$ zloty) (6)

\begin{tabular}{|c|c|c|c|c|}
\hline $\begin{array}{l}\text { Sources: } \\
\text { Uses }\end{array}$ & $\begin{array}{l}\text { Central Budget } \\
\text { (MOH) }\end{array}$ & $\begin{array}{l}\text { Regional Budget } \\
\text { (MOF) }\end{array}$ & Other & Private \\
\hline Outpatient & (negligible) & $17,332,969.00$ & & \\
\hline -Salary & & $13,844,336.00$ & & \\
\hline -Drugs & & $732,817.00$ & & \\
\hline -Maintenance & & $2,343,806.00$ & & \\
\hline -Other & & $411,993.00$ & & \\
\hline Inpatient & $6,017,004.00$ & $36,278,077.00$ & & \\
\hline -Salary & $3,278,092.00$ & $23,351,051.00$ & & \\
\hline -Drugs & $973,301.00$ & $4,302,941.00$ & & \\
\hline -Maintenance & & $6,786,951.00$ & & \\
\hline -Food & $1,489,410.00$ & $1,030,040.00$ & & \\
\hline -Other & $1,616,671^{*}$ & $807,094.00$ & & \\
\hline Medical Colleges & $2,402,549.00$ & & & \\
\hline Central Programs & $531,537.00$ & & & \\
\hline Central Exp. on Drugs & $6,846,202.00$ & & & \\
\hline $\begin{array}{l}\text { Other Central } \\
\text { Expenditure }^{\star *}\end{array}$ & $3,593,193.00$ & & & \\
\hline $\begin{array}{l}\text { Other Regional } \\
\text { Expenditure }^{\star \star \star}\end{array}$ & & $18,691,290.00$ & & \\
\hline Total & $13,980,485.00$ & $72,302,336.00$ & & \\
\hline
\end{tabular}




\section{Purpose of the Present Study}

Very few estimates of health expenditure have been made in Poland. Tymowska (3) estimates total health expenditure, public and private, as being around $5.7 \%$ of GDP in 1983 , falling to $3.89 \%$ in 1988 and again climbing to $5.26 \%$ in $1992(7,8)$. Latest estimates available for 1993 indicate another decline, to $4.87 \%$ of $\operatorname{GDP}(7,8)$. Tymowska (3) estimates private expenditure to be around $9 \%$ of total expenditure on health, equivalent to about $0.5 \%$ of GDP in the early 1980s. Chellaraj et al (7) estimate private expenditure to be constituting $1.06 \%$ of GDP in 1993. Both of these studies use national statistics on consumption patterns to identify private payments for medical goods and pharmaceuticals, and for medical services. One problem with using these statistics on consumption patterns is that out-of-pocket payments for medical services are reported only for expenditure on drugs and visits made to private or co-operative health service institutions, nursing homes for elderly persons and nurseries that take care of children (3). Thus, while these statistics provide estimates for categories reported, they ignore out-of-pocket payments made by individuals in public facilities.

Out-of-pocket payments in public clinics and hospitals can be expected to be quite substantial, since while annual public health expenditures have declined in real terms over the period 1987-1993, the incidence of use has steadily increased. Inpatient visits have been increasing at an average annual rate of $2.15 \%$ and total number of inpatient days have recorded an average annual increase of $1.2 \%$. At the same time, outpatient visits per person have also remained steady over the years. It is reasonable to expect that the net effect of increased demand would translate into the requirement of more resources, yet none of the studies on health financing in Poland show where the additional resources are coming from.

In this paper we employ the results obtained from a survey conducted by the Department of Environment and Social Services (DESS) in 1994, and reported in Zajenkowska-Kozlowska (9), to estimate out-of-pocket payments and to fill this gap in existing studies. 


\section{Survey: Purpose and Methodology}

The Main Statistics Office of the Department of Environment and Social Service conducted a survey in the fourth quarter of 1994 on family health and expenditure on health care. A sample of 3,845 families comprising 12,359 people was drawn from the country as a whole using the principles of stratified random sampling. As a first step the population was stratified on the basis of demographic and socio-economic criteria (such as income and expenditure levels, urbanization, gender, age groups etc.) and on the basis of employment. The final sample was drawn randomly from these strata, so that the composition of the sample closely resembles that of the population. Thus, the sample is deemed representative of the country as a whole, but not necessarily of a voivod.

The purpose of the survey was to (a) make an assessment of the state of health of the people; and (b) estimate family and individual health expenditure on family health care. All questions in the survey were addressed to individuals 15 years and older and the unit of sample was the household.

Assessment of health was done according to responses on a three-point scale of very good, average and $\mathrm{bad} / \mathrm{very}$ bad. $60 \%$ of the people surveyed assessed their health to be very good, $25 \%$ rated their health as average and $15 \%$ assessed their health to be bad or very bad. In making an assessment of expenditures, out-of-pocket payments by individuals were taken into account for five kinds of health care services: inpatient services, physician consultations, dental visits, medical tests and rehabilitation therapy. In computing average expenditures, the median estimates were used. Thus, all estimates used in this study are also based on median average. 


\section{National Health Accounts Revisited}

The survey yields information on annual out-of-pocket spending on health care by individuals and households, both on outpatient care and inpatient care, as well as on dental visits, drugs, rehabilitation and others. On an average, annual per capita out-of-pocket health expenditure on health care in 1994 was $1,369,400$ zloty (henceforth zI.), or US\$ 56.19. On the other hand, the government spent 2,238,205 zl. (US\$ 91.84) per person. In other words, out-of-pocket expenditure accounted for $38 \%$ of total expenditure on health.

A large percentage (92\%) of out-of-pocket expenditure was incurred on non-hospital based health care. Besides physician visits, this also includes drugs purchased over the counter, rehabilitation and other expenditures, such as on reading glasses, hearing aids etc., categorized as "other" in the table below. On the other hand, hospital-based care accounts for $49 \%$ of public health expenditure.

Table 2: Health Care Expenditure, 1994 (Sources and Use, in million zl., current values)

\begin{tabular}{|l|l|r|l|r|r|r|}
\hline & Public & \% of GDP & Private & \% of GDP & \multicolumn{1}{l|}{ Total } & \% of GDP \\
\hline Inpatient & $42,295,081$ & 2.04 & $4,454,400$ & 0.21 & $46,749,481$ & 2.25 \\
\hline Outpatient & $17,332,969$ & 0.83 & $36,607,080$ & 1.76 & $53,940,049$ & 2.59 \\
\hline Other & $26,654,771$ & 1.28 & $11,888,820$ & 0.57 & $38,543,591$ & 1.85 \\
\hline Total & $\mathbf{8 6 , 2 8 2 , 8 2 1}$ & $\mathbf{4 . 1 5}$ & $\mathbf{5 2 , 9 5 0 , 3 0 0}$ & $\mathbf{2 . 5 4}$ & $\mathbf{1 3 9 , 2 3 3 , 2 1 1}$ & $\mathbf{6 . 6 9}$ \\
\hline
\end{tabular}

Source: Ministry of Health and Ministry of Finance, Poland, 1994; Zajenkowska-Kozlowska, 1996.

Thus, out-of-pocket expenditure on inpatient care constitutes only $8.4 \%$ of total private expenditure and $9.5 \%$ of combined public and private expenditure on inpatient services. On the other hand, private expenditure on physician consultations (including dental visits and drugs) is $70 \%$ of total private expenditure and $68 \%$ of combined public and private expenditure on outpatient services (including dental visits and drugs). 


\section{Survey Findings on Out-Of-Pocket Expenditure}

\section{(a) Inpatient Services}

The survey results indicate that $7.3 \%$ of the sample used inpatient services in hospitals and sanatoriums in the past one year. Of those using inpatient services, $85 \%$ used inpatient hospital services once a year, $12 \%$ twice a year, $2.3 \%$ three times a year, and $1.3 \%$ more than three times a year. Women use inpatient services more often than men.

Of those using inpatient hospital services, $87 \%$ sought care in general hospitals, $10 \%$ in health resorts and $3 \%$ in specialized hospitals including psychiatric hospitals. Of those using general hospitals, $83 \%$ frequented hospitals in the region of their voivod, while $17 \%$ went to hospitals in other voivods. This information is useful for policy makers, since the ability to claim reimbursement for patients from other voivods is a prominent focus of reforms currently under consideration.

The average length of stay in a hospital in 1994 was 15 days and, excluding repeat admissions, $5.5 \%$ of the sample surveyed used inpatient general hospital services in the past year. Of those using inpatient hospital services, $33 \%$ of the patients suffered from serious disability, $25 \%$ were hospitalized due to chronic illness, $10 \%$ were accident cases, and the remaining $32 \%$ were specific illness episode cases.

In 1994, a patient spent on an average 1.16 million zl. for one episode of hospitalization, with expenditures ranging from a low of 10,000 zl. to a high of 23.4 million zl. Typical areas of expenditures included voluntary donations made by patients to hospitals, payment for bedside duties to nurses and other staff (these payments are prescribed and regular), drugs, food, travel, other obligatory fees, and gratuitous payments to the medical staff, or 'envelope money'. Not all patients spent on all these items, though almost $92 \%$ of all hospital dealings had some costs for the patient. It is interesting to note that more patients $(69 \%)$ made envelope payments to physicians in non-regional hospitals than in regional hospitals $(61 \%)$. Similarly $58 \%$ of patients in non-regional hospitals made envelope payments to other staff, as compared to $50 \%$ in regional hospitals. 
Table 3. Average Expenditure per Patient for Hospital Inpatient Services, 1994

\begin{tabular}{|l|r|l|r|}
\hline Item of Expenditure & $\begin{array}{l}\text { Average amount } \\
\text { (thousand zl.) }\end{array}$ & $\begin{array}{l}\text { Minimum } \\
\text { (thousand zl.) }\end{array}$ & $\begin{array}{l}\text { Maximum } \\
\text { (thousand zl.) }\end{array}$ \\
\hline Voluntary payments & 236 & 8 & 3200 \\
\hline Bedside Duties & 526 & 50 & 2500 \\
\hline Drugs & 468 & 10 & 5600 \\
\hline Food & 533 & 25 & 800 \\
\hline Travel & 897 & 100 & 9600 \\
\hline Envelope Payment: Physicians & 765 & 30 & 1500 \\
\hline Envelope Payment: Other Staff & 260 & 10 & 800 \\
\hline $\begin{array}{l}\text { Uninsured patients (unregistered } \\
\text { unemployed, foreigners, etc.) }\end{array}$ & 3900 & 100 & 20000 \\
\hline Other & 411 & 30 & 4300 \\
\hline
\end{tabular}

Source: Zajenkowska-Kozlowska, 1996.

We present the breakdown of out-of-pocket expenditures in two different ways. Table 3 shows the average (median) and range of expenditure on different items of those patients who spent in that category. Thus, patients who had any spending on voluntary payments reported expenditure in this category ranging from $8,000 \mathrm{zl}$. to 3.2 million $\mathrm{zl}$., for a median expenditure of $236,000 \mathrm{zl}$. In order to obtain an estimate of average (median) expenditure per patient across the entire population, irrespective of whether a patient has any expenditure or not, we present the breakdown of average expenditures in table 4 . The breakdown shows that envelope payments to physicians account for $37 \%$ (median expenditure 432,000 zl.) and envelope payments to other staff $9 \%$ (median expenditure 104,000 zl.) of total expenditure. Drugs purchased by patients accounted for $13.9 \%$ (median expenditure $161,000 \mathrm{zl}$.) of all expenditures, followed by voluntary donations to hospitals $(7.6 \%$, median expenditure $87,000 \mathrm{zl}$.) and travel and other expenses (7.4\%, median expenditure 86,000 $\mathrm{zl}$.). 
Table 4. Average Expenditure per Patient in a General Hospital, 1994

\begin{tabular}{|l|r|r|}
\hline Item of Expenditure & $\begin{array}{l}\text { Average amount } \\
\text { (thousand zl.) }\end{array}$ & Percentage of Total \\
\hline Voluntary Payments & 87 & 7.5 \\
\hline Bedside Duties & 25 & 2.2 \\
\hline Drugs & 161 & 13.9 \\
\hline Food & 237 & 20.4 \\
\hline Envelope Payment: Physicians & 432 & 37.2 \\
\hline Envelope payment: Other staff & 104 & 9.0 \\
\hline Uninsured patients & 28 & 2.4 \\
\hline Travel and Other Expenses & 86 & 7.4 \\
\hline Total & $\mathbf{1 1 6 0}$ & $\mathbf{1 0 0}$ \\
\hline Source: Zajenkowska-Kozlowska, 1996. & & \\
\hline
\end{tabular}

\section{(b) Physician Visits}

The survey results indicate that a total of 16,400 physician visits were recorded in the fourth quarter of 1994, at an average annual rate of 5.4 visits per person. About half of those surveyed made no visits at all during the quarter, while the remaining half made at least one visit. Women recorded 1.5 visits on average, and men made an average of 1.1 visits to the physician. Disabled and chronically ill patients visited physicians 2.5 times above average, making about 3.25 visits per patient. Non-disabled but chronically ill patients made 3.12 visits, 2.4 above average. Patients who had occasional accidents or illness visited 2.2 times more than average, i.e., 2.9 visits per patient. $78 \%$ of all patients who sought care frequented regional government clinics, $16 \%$ frequented private clinics, and $6 \%$ sought care from physicians outside the region. The primary reason for using non-regional clinics, as cited by $37 \%$ of those surveyed (42\% of the rural sample), was the availability of 'better' physicians outside the region. $29 \%$ of those surveyed cited better attitude in non-regional clinics, $15 \%$ maintained that there was a shortage of physicians in their region, $15 \%$ felt that there was better equipment in clinics outside their region, while $9 \%$ said there was a long waiting line in their regional clinics.

On an average, a patient visiting a physician clinic spent $46,000 \mathrm{zl}$. per visit, ranging from a low of $10,000 \mathrm{zl}$. in regional clinics to $66,000 \mathrm{zl}$. in non-regional clinics and $217,000 \mathrm{zl}$. in private clinics.

\section{(c) Dental Visits}

The survey results indicate that in the fourth quarter of 1994 only $23 \%$ of the population visited a dentist, for an annual average of 2.2 dental visits per person. People in the age group of 10 to 39 years had the highest number of visits.

The average expenditure per visit was $118,000 \mathrm{zl}$., ranging from $93,000 \mathrm{zl}$. for a regular visit to 283,000 zl. for an orthodontic and prosthetic visit. The main item of expenditure on dental visits within the region was envelope payment, accounting for $40 \%$ of all expenditures. Envelope payments accounted for only $11 \%$ of total expenditure in non-regional clinics and $1.3 \%$ in private clinics, the major items being travel and fees, respectively. 


\section{(d) Other Medical Treatment and Costs}

Diagnostic tests and laboratories account for $60 \%$ of the residual costs. On average, a patient spends $10,000 \mathrm{zl}$. for electro-cardiogram (EKG) and ultra-sonography (USG) in regional centers, $50,000 \mathrm{zl}$. in non-regional centers, and $200,000 \mathrm{zl}$. in private centers. Similarly, X-rays cost 4,500 zl. in the regional clinics, 20,000 zl. in non-regional clinics and 148,000 zl. in private clinics.

\section{(e) Envelope Payments}

The practice of informal payments began around the end of the 1970s. While officially medical treatment was provided free of charge, patients started making informal payments to physicians in order to obtain faster and more personal service. By the end of the 1980s, this system of informal payments, or "envelope money" as it came to be called, gained widespread acceptance. The survey results provide some interesting information on envelope payments made by patients in general hospitals. On average, $46.2 \%$ of all expenditure incurred by a patient in one episode of hospitalization is on envelope payments. The median amount of envelope payments made by a patient is 536,000 zl., of which $432,000 \mathrm{zl}$. (81\%) is paid to physicians and the rest to other medical and para-medical staff. In 1994, 4.4 million patients sought treatment in general hospitals, contributing 2,364,879.17 million zl. as envelope payments. Total expenditure of all general hospitals on gross salaries in 1994 was 23,351,051 million zl. Envelope payments therefore supplemented the earnings of medical personnel by about $10 \%$ of their gross salaries, or over $15 \%$ of their take-home cash salaries. There were 80,570 physicians in government employment in 1994. On average, therefore, envelope payments contributed 23.78 million zl. to each physician's annual salary, which is more than double of the annual average gross salary of a physician which, in 1994, was approximately 11 million zl. Clearly, envelope payments are a significant source of earnings for physicians.

The survey also shows that patients were more likely to make envelope payments in non-regional hospitals than in their own voivod hospitals, and on an average paid three times as much in non-regional hospitals, both for physicians as well as for other staff. Unfortunately, there is no information on envelope payments in outpatient clinics and medical academies. 


\section{Discussion}

The survey conducted on out-of-pocket spending on health in Poland by the Department of Environment and Social Services in 1994 provides better information than has been previously available $(3,7,8)$. Not surprisingly, the survey results show that health care expenditures in Poland are higher than has been usually maintained, and that private expenditure on health is a significant proportion of total expenditure on health.

Widely used figures show government spending on health in Poland increasing from $4.36 \%$ of the GDP in 1990 to $5.26 \%$ in $1992(7,8)$ and falling again to $4.15 \%$ in $1994(10,11)$. In the absence of any reliable information on private spending, these figures have usually been understood to reflect total spending on health care in Poland $(7,8)$, though Tymowska (3) assumes an additional $0.5 \%$ of GDP spending from private expenditures. The DESS 1994 survey results show that-private spending on health care accounted for over $2.5 \%$ of GDP in 1994, taking the total expenditure to almost $6.7 \%$ of GDP. This figure is comparable to modest levels of spending amongst OECD members and well above levels of spending estimated for Central and Eastern European countries, where private spending is also probably underestimated. This new information has a number of substantive implications for our understanding of the performance of Poland's health care system and the development of reform strategies.

In terms of overall health system performance, the high out-of-pocket spending in Poland probably reflects three important trends. First, while during the 1960s, ' 70 s and early ' 80 s, Poland achieved substantial health care coverage and improvement in health status via a socially financed national health service, during the 1980 s this system began a substantial decline. -Economic decline produced fiscal pressures forcing lower public spending on health. Second, and simultaneously, an aging population and rising expectations, particularly after the transition to a market-based economy, increased demand for health care. Third, while such pressures were not unfamiliar in other European countries, Poland was unable to mount a successful organized response to them, either via new resource mobilization or by sensible cost containment. Rather, Poland met the resultant resource gap through increased out-ofpocket spending and declining quality of public services. This situation is not unfamiliar to students of health care systems in developing economies. Indeed, Poland might be characterized as having a developing country health financing system trying to support population demands and health care services of a more advanced country.

This situation reported in Poland is likely to be true for other transitional economies as well. The presence of sizeable "informal" payments in other Central and Eastern European countries is also widely reported and, as our analysis suggests, such payments may be larger than supposed. Other transitional economies of Central and Eastern Europe and the Former Soviet Union may have much higher levels of total health spending as well. Thus, some of the implications for Poland discussed below may have wider application.

In Poland, outpatient services account for more than half of total spending: a pattern closer to that of developing countries than OECD members. The role of private health spending differs significantly between inpatient and outpatient expenditures. More than $90 \%$ of private spending on health in Poland is on health and related services purchased outside the hospital, leaving less than $10 \%$ for inpatient services. In contrast, public spending is divided equally between hospital-based and nonhospital-based care. Consumers of health care seem to have a greater willingness and capacity to bear the relatively low cost of outpatient services (and probably obtain them faster) than to invest in the more costly hospital-based services. 
However, hospital capacity and use in Poland is also on the high end of European comparisons (12) and clinical quality has suffered. Given declining health status and emerging public health problems $(7,8)$, what implications can one derive for future public action in health care financing? While the total resources spent on primary care is much larger than previously thought, these resources are poorly organized and may not contribute as much as possible to total health improvement. This suggests that greater attention should be given to socially organizing a larger share of total health care finance and using it to assure a more integrated delivery of appropriate services.

Indeed, in 1997 Poland passed legislation to establish a new national health insurance scheme, due to take effect from January 1, 1999. However, this scheme may not adequately address the problems posed by the private, unregulated part of Poland's health care system. The current version of the (Polish) General Health Insurance Act, 1997, mandates a premium contribution of $10 \%$ of annual individual income. This contribution is then fully deductible from personal income-tax, effectively nullifying any additional individual contributions. In other words, the general health insurance in Poland is proposed to be funded by a transfer from tax revenues without any contribution from the beneficiary, even though there exists substantial evidence of individual ability and willingness to pay for health care. Recognizing the current levels of private spending, policy-makers in Poland can thus make a case for raising additional revenues from households, if they can successfully replace out-of-pocket spending with insurance benefits.

Unfortunately, the current system of out-of-pocket payments will make such restructuring difficult, as it threatens the interests of many providers and patients. For example, salaries of physicians in Poland in 1994 were on average 18\% lower than the national average salary and $23 \%$ lower than salaries in the industries sector. With envelope payments contributing roughly twice the physician's salary, total physician income has become much higher than other salaried professions. Senior physicians are likely to have significantly higher earnings from envelope payments as compared to junior physicians, and are thus less likely to favor changes in the manner in which physicians are paid for services provided. At the same time, the prevalence of informal payments favors multiple employment by public sector physicians, who have strong incentives to have their own private clinics and yet little reason to leave the government job that provides such high earnings. It will not be easy to wean providers from these benefits and their control over them.

Any reforms in provider payment methods following the introduction of national insurance will have to contend with the sizeable informal payments that many providers receive in the current system. Innovations in provider payment methods that will guarantee provider participation will require mobilization of new resources so as to maintain physician income at present levels. Total health expenditure will be contained only if these additional resources come from the pool currently financing informal payments; any other source of funds will only serve to increase current spending levels.

How will patients react to these changes? Eliminating current levels of informal payments would probably appeal to patients in principle, but they must be convinced that they will receive better services in return. Survey findings on the extent and scope of informal or envelope payments suggest that private spending is potentially a significant determinant of the nature and extent of health care and attention patients get from physicians. Physicians receiving informal payments probably provide additional, out-of-turn, and more personalized services for their patients; and in a system where both physicians and patients have come to understand the advantages of informal payments, any change therein may require many attitudinal adjustments.

The survey findings clearly indicate the need for a better understanding of the current availability and distribution of resources in the health sector and their directions of flow, in both public and private sectors. Careful search has shown that such information is available in Poland, though many contemporary studies continue to lament the paucity of data and information on private spending in health care. It is likely that such information may also be available in other Central and Eastern European countries and, as this analysis indicates, it certainly would be very useful to obtain such data. 
Such information on expenditures can then be effectively used for a variety of purposes connected with policy formulation, planning and management. One way of documenting and analyzing these changes in health expenditures is the system of National Health Accounts (NHA). Carried out periodically, NHA can be used to track and monitor changes in the financing of the health care system (4), and provide analysis that may better inform future policy statements. 


\section{References}

1. Chawla, Mukesh and Dorota Kawiorska, Analiza wydatkow rzadowych w zakresie ochrony zdrowia w Polsce w latach 1960-1990, Antidotum - zarzadzanie w opiece zdrowotnej, 1997, vol.VI, no. 1, pages 36-45.

2. This includes expenditure on drugs and salaries of medical staff working in parallel health services, like Railways, Education, Industry, etc., but excludes nonmedical salaries, maintenance, and capital outlays, that are financed by the respective ministries. We do not have an estimate of health budgets of parallel ministries at this time. However, an idea of the magnitude of non-medical staff salaries and other expenses can be obtained by looking at the budget of St. Jan Grande Hospital in Krakow, where nonmedical staff salaries and other expenses accounted for $56 \%$ of the total budget of the hospital in 1995 .

3. Tymowska, Katarzyna, Health Services Financing in Poland, International Journal of Health Planning and Management, 1987, volume 2, 147-157.

4. Berman, Peter, National Health Accounts in Developing Countries: Appropriate Methods and Recent Applications, Health Economics, 1997, volume 6: 11-30.

5. National Health Accounts (NHA) are a tool to assess health expenditures, and describe the expenditure flows, both public and private, within the health sector of a country. They describe the sources, uses and flow of funds within the health system, and thus provide information on allocation and mobilization of health sector resources. "Sources" of financing might include the Ministry of Finance, donors, employers, and households. Financing intermediaries might include the Ministry of Health, the Ministry of Education, donors, other ministries, social insurance funds, firms, private insurers, and households. Finally, the "Uses" category may include a combination of types of services (acute hospital care, physicians' services) and types of providers (psychiatric hospitals, nursing homes). For details, see Berman (4).

6. On January 1, 1995, the zloty was revalued, so that 1 new 1995 zloty (PNZ) equals 10,000 old zloty. In this paper all figures are in old zloty.

7. Chellaraj, G, Olusoji Adeyi, Alexander S. Prekker, and Ellen Goldstein, Trends in Health Status, Services, and Finance: The Transition in Central and Eastern Europe, Volume II, World Bank Technical Paper number 348, 1996, The World Bank, Washington D.C.

8. Goldstein, Ellen, Alexander S. Prekker, Olusoji Adeyi and G. Chellaraj, Trends in Health Status, Services, and Finance: The Transition in Central and Eastern Europe, Volume I, World Bank Technical Paper number 341, 1996, The World Bank, Washington D.C.

9. Zajenkowska-Kozlowska, Alicja, Zdrowie w Rodzinie i Wydatki na Ochrone Zdrowia W 1994r, Main Statistics Office, Department of Environment and Social Services, Government of Poland, 1994.

10. Ministry of Health, Poland, 1996, Budget and Expenditure Statement.

11. Ministry of Finance, Poland, 1996, Budget and Expenditure Statement.

12. OECD, Health Care Reform: The Will to Change, Health Policy Studies no. 8, 1996. 